\title{
Zonas de Agroecologia e Ecovilas: uma proposta para os planos diretores municipais
}

Zones of Agroecology and Ecovillages: a proposal for

municipal zoning plans

Rebeca Roysen $^{1}$ (i) https://orcid.org/0000-0003-4368-9218

Beatriz Martins Arruda2 (D) https://orcid.org/0000-0002-5791-9988

Roberto Ferreira $^{3}$ (D) https://orcid.org/0000-0003-3367-627X

Renata Amorim Almeida Fonseca 4 (i) https://orcid.org/0000-0001-5056-2114

Maria A. A. Alvarenga 5 (D) https://orcid.org/0000-0001-8824-2845

Luiz Guilherme Mafle Ferreira Duarte ${ }^{6}$ (D) https://orcid.org/0000-0003-0686-9690

\begin{abstract}
Resumo
Ecovilas são assentamentos humanos sustentáveis criados pela sociedade civil que respondem aos Objetivos do Desenvolvimento Sustentável da Organização das Nações Unidas e desenvolvem soluções inovadoras em diversas dimensões da sustentabilidade. No entanto, a dicotomia urbano-rural que permeia a legislação brasileira, no que tange ao uso e ocupação do solo, dificulta a expressão de novas ruralidades e o desenvolvimento das ecovilas. O presente artigo esclarece o papel das ecovilas na busca pelo desenvolvimento sustentável, problematiza as dificuldades causadas pelo atual ordenamento jurídico brasileiro, bem como indica um possível caminho para que as ecovilas sejam recepcionadas pela legislação como um ator social relevante na busca pela sustentabilidade local. Esclarecemos de que forma as ecovilas podem ser inseridas nos Planos Diretores Municipais, por meio da criação de "Zonas de Agroecologia e Ecovilas". Por fim, definimos critérios claros para orientar os gestores públicos na identificação das ecovilas existentes em seus territórios.
\end{abstract}

Palavras-chave: Plano Diretor, Ecovilas, Sustentabilidade, Novas ruralidades, Desenvolvimento local.

\begin{abstract}
Ecovillages are sustainable human settlements created by civil society that address the UN's sustainable development goals and develop innovative solutions in different dimensions of sustainability. However, the urban-rural dichotomy that permeates Brazilian legislation related to land use and occupation hinders the expression of new ruralities and the development of ecovillages. This essay clarifies the role of ecovillages in sustainable development, problematizes the difficulties caused by Brazil's current legal framework, and indicates a possible path for the inclusion of ecovillages in the legislation as a relevant social actor in the efforts towards local sustainability. We clarify how ecovillages can be included in Municipal Zoning Plans through the creation of "Zones of Agroecology and Ecovillages". Finally, we define clear criteria to guide public managers in identifying the existing ecovillages in their territories.
\end{abstract}

Keywords: Zoning Plan. Ecovillages. Sustainability. New ruralities. Local development.

1 Universidade da Basiléia, Centro para Religião, Economia e Política, Nadelberg 10, 4051 Basiléia, Suíça. Correspondência para/Correspondence to: R. ROYSEN. E-mail: rebecaroysen@gmail.com

2 Universidade Estadual de Campinas, Faculdade de Engenharia Civil, Arquitetura e Urbanismo, Programa de Pós-graduação em Engenharia Civil. Campinas, SP, Brasil.

3 Universidade Federal do Rio Grande do Sul, Escola de Administração, Programa de Pós-graduação em Administração. Porto Alegre, RS, RJ, Brasil.

4 Universidade Federal do Rio de Janeiro, Instituto de Psicologia, Programa de Pós-graduação em Psicossociologia de Comunidades e Ecologia Social. Rio de Janeiro, RJ, Brasil.

${ }^{5}$ Fundação IBI Tecnologia Alternativa. Araxá, MG, Brasil.

${ }^{6}$ Pontifícia Universidade Católica de Minas Gerais, Faculdade de Psicologia. Poços de Caldas, MG, Brasil. 


\section{Introdução}

O artigo 225 da Constituição Federal Brasileira afirma que: "Todos têm direito ao meio ambiente ecologicamente equilibrado, bem de uso comum do povo e essencial à sadia qualidade de vida, impondo-se ao poder público e à coletividade o dever de defendê-lo e preservá-lo para as presentes e futuras gerações" (Brasil, 1988, Art. 225). A presente pesquisa busca esclarecer o papel das ecovilas na realização desse princípio constitucional e como ele pode ser estimulado pelo poder público e pela sociedade civil.

As ecovilas são um modelo de assentamento humano sustentável que se une ao leque de iniciativas da sociedade civil que têm emergido ao redor do mundo nas últimas décadas, propondo outros modos de viver. Essas iniciativas oferecem soluções factíveis para o desenvolvimento sustentável e por isso têm recebido cada vez mais atenção pela comunidade científica internacional. Porém, elas ainda são negligenciadas pelas políticas públicas. No Brasil, as ecovilas esbarram em diversas dificuldades legais para se estabelecer e desenvolver suas atividades.

O foco deste artigo é problematizar a dicotomia urbano-rural que permeia a legislação brasileira e propor um conjunto de critérios que possa fundamentar a inserção das ecovilas no ordenamento territorial brasileiro. Para tanto, após esta (1) introdução, apresentamos: (2) a metododologia empregada; (3) o conceito de ecovilas e a sua relação com as quatro dimensões da sustentabilidade que conferem-lhes reconhecimento internacional como modelo de assentamento sustentável; (4) as redes de ecovilas global, continentais e nacionais. A seguir, (5) discutimos como a nova ruralidade emergente com as ecovilas enfrenta desafios de ordem jurídica para a sua regularização fundiária no Brasil; (6) apresentamos uma proposta para a inserção das ecovilas no ordenamento jurídico brasileiro, regulamentada por meio da criação de Zonas Agroecologia e Ecovilas (ZAE) nos Planos Diretores Municipais (PDM); e oferecemos (7) um conjunto de parâmetros orientadores para auxiliar gestores públicos na identificação e caracterização das ecovilas, de forma a distingui-las de empreendimentos imobiliários que, por ventura, adotem o mesmo nome, mas não incluam nem os fundamentos teóricos nem as práticas sociais, culturais, econômicas e ambientais propostos pelas ecovilas. Por fim, na seção (8) fazemos algumas considerações finais.

\section{Materiais e Metódos}

Este artigo foi coletivamente construído por pesquisadores que têm estudado sobre ecovilas no Brasil e no mundo e recebeu contribuições de membros de ecovilas brasileiras, articulados por meio da rede brasileira do Conselho de Assentamentos Sustentáveis da América Latina (CASA Latina), chamada de Rede CASA Brasil, ambas integradas à rede global de ecovilas GEN (Global Ecovillage Network). A motivação para esta pesquisa surgiu da experiência concreta dos membros da rede brasileira com as dificuldades enfrentadas pelas ecovilas rurais 
quanto à inadequação de seus modelos de ocupação da terra à legislação vigente. Baseamonos, também, na experiência de uma das co-autoras (Maria Alvarenga) que desenvolveu propostas para os PDM de dois municípios mineiros, Esmeraldas e Alvorada de Minas, para solucionar tais dificuldades. Realizou-se, então, uma pesquisa exploratória bibliográfica e documental que recorreu à literatura científica e à legislação para descrever conceitualmente as ecovilas e explicar a sua relevância para o desenvolvimento territorial sustentável. Pautados pela lógica indutiva, com abordagem qualitativa, oferecemos um subsídio teórico-conceitual para que os envolvidos nas discussões dos PDM possam introduzir mudanças a partir dos resultados aqui apresentados, o que caracteriza a natureza da pesquisa como aplicada.

\section{Ecovilas e o desenvolvimento sustentável}

Ecovilas são comunidades orientadas para a sustentabilidade da vida. São frequentemente constituídas por grupos de pessoas que se unem para desenvolver e partilhar atividades que visam à regeneração dos ecossistemas e dos contextos socioculturais nas quais elas se inserem (Roysen; Mertens, 2016; Santos-Júnior, 2016). A emergência dessas comunidades é inspirada pelos movimentos de contracultura das décadas de 1960/70 e por outros movimentos comunais que se manifestaram como alternativas de vida em momentos de crise, reunindo pessoas que não se identificavam com as formas de pensamento e estilos de vida dominantes (Capello, 2013; Dawson, 2013; Matheus e Silva, 2014; Santos-Júnior, 2016). No contexto da globalização, na qual os problemas socioambientais amplificam-se, o tipo de assentamento humano proposto pelas ecovilas é uma forma contemporânea de expressão da ideia de que a própria sociedade civil pode protagonizar as mudanças necessárias para a construção de um futuro mais sustentável, resiliente e equitativo.

Usualmente, as ecovilas tendem a agregar as diversas áreas do viver humano (educação, saúde, economia, construção, agricultura, energia, gestão, política etc.) em um modo de habitar integrado ao meio ambiente (Santos-Júnior, 2016). Elas são frequentemente conceituadas em torno de quatro dimensões interligadas: ecológica, social/comunitária, econômica e cultural/espiritual (Gaia Education, 2005).

A dimensão ecológica é o esforço comunitário pela redução dos impactos ambientais negativos da ocupação e uso do território, bem como por uma maior eficiência no uso e cuidado dos bens naturais comuns. Essa dimensão se manifesta no desenvolvimento de diversas práticas locais regenerativas, tais como: bioconstrução, permacultura, tratamento ecológico dos resíduos domésticos, captação de água da chuva, compostagem dos resíduos orgânicos, produção orgânica de alimentos, geração de energia limpa/renovável, entre outros (Swilling; Annecke, 2006; Matheus e Silva, 2014).

A dimensão social/comunitária corresponde ao desejo das pessoas de construírem relacionamentos pautados pela confiança e ajuda mútua e se manifesta em práticas de 
autogestão, processos participativos de tomada de decisão, práticas de partilha emocional, compartilhamento de ferramentas, almoços comunitários, carros coletivos, entre outros (Kirby, 2003; Christian, 2007; Loezer, 2011; Kunze, 2015; Roysen; Mertens, 2016; 2019).

A dimensão cultural/espiritual, embora varie muito de grupo para grupo, é a percepção de que a busca pelo autoconhecimento, a mudança de valores e a tomada de consciência são partes indissociáveis do caminho para a sustentabilidade (Roysen, 2018). Essa dimensão se expressa em rituais, práticas meditativas e espirituais (Kasper, 2008; Caravita, 2012). A dimensão cultural/espiritual envolve questões profundas de significado e sentimento de pertencimento próprias ao ser humano (Litfin, 2014). Mesmo se apresentando com diferentes formatos e soluções, em diferentes culturas e sociedades, essas comunidades estão unidas por um sistema de valores que busca superar divisões convencionais de raça, religião e cultura (Jackson, 2004).

A dimensão econômica nas ecovilas se relaciona à emergência de práticas colaborativas de trabalho e gestão baseadas em atividades produtivas diversificadas. O uso multifuncional do território integra produção agrícola, turismo de base comunitária, projetos educativos e culturais, voluntariado, etc. As ecovilas não se enquadram, portanto, na definição de zona rural como área de produção estritamente agropecuária. Mutirões, trocas, criação de moedas sociais, propriedade coletiva da terra e das ferramentas, e geração de renda por meio de práticas regenerativas (agricultura orgânica, fabricação de produtos naturais, cursos para a difusão de práticas sustentáveis etc.) são algumas das atividades produtivas promovidas pelas ecovilas (Roysen, 2018).

Justamente por serem locais de intensa experimentação com práticas e tecnologias sociais inovadoras, e por seu foco em atividades de educação para a sustentabilidade, as ecovilas são descritas na literatura acadêmica como "nichos de inovação social de base" (Roysen; Mertens, 2019; Boyer, 2015), como "incubadoras de inovações sociais" (Kunze, 2015), como "laboratórios vivos" (Santos-Júnior, 2016), como "centros demonstrativos" em práticas sustentáveis (Salazar, 2013) e como um "paradigma alternativo de desenvolvimento" (Veteto; Lockyer, 2008). É importante ressaltar, também, que uma ecovila é um processo e não apenas um resultado final, podendo levar anos para que essas organizações alcancem maturidade institucional e sustentabilidade nas quatro dimensões. Com o tempo, tornam-se poderosos agentes de mudança da sociedade, regenerando seus ambientes naturais, preservando o patrimônio cultural, aumentando a resiliência social e diversificando os meios de subsistência.

Diversos estudos indicam que, de um modo geral, essas comunidades apresentam um melhor desempenho ambiental quando comparadas a comunidades convencionais (Boyer, 2016; Belleze et al., 2017; Daly, 2017; Sherry, 2019). Um estudo recente sobre ecovilas nos EUA demonstra que seu modo de vida promove um impacto ambiental entre $47 \%$ e $80 \%$ menor do que o impacto de um norte-americano médio (Sherry, 2019). Grande parte dessa redução do 
impacto ambiental se dá por meio da integração de práticas sustentáveis diversas e pelo compartilhamento organizado de recursos, tais como carros, refeições, espaços, ferramentas, etc., que implicam em uma redução de consumo (Sherry, 2019). No Brasil, ao aplicar onze Indicadores de Desenvolvimento Sustentável (IDS) estabelecidos pelo Instituto Brasileiro de Geografia e Estatística (IBGE) às ecovilas brasileiras, Belleze et al. (2017) concluíram que as ecovilas apresentam melhores desempenhos em todos os IDS calculados, em comparação com a população brasileira.

Essas evidências demonstram o potencial das ecovilas como um modelo de ocupação e uso sustentável do território. Elas surgem, portanto, como uma alternativa aos padrões insustentáveis das sociedades modernas. As ecovilas são consideradas pela Organização das Nações Unidas (ONU) como um dos mais sustentáveis modelos de comunidade no planeta (United Nations, [20--]). A ecovila de Findhorn, por exemplo, figura entre as "melhores práticas de desenvolvimento sustentável" compiladas pela agência Habitat da ONU, responsável por promover cidades social e ambientalmente sustentáveis (Mattos, 2015; UN-HABITAT, 2017).

As ecovilas são laboratórios de inovações e tecnologias sociais para a sustentabilidade, adaptáveis a cada contexto territorial, desenvolvidas e testadas na microescala das comunidades. Com isso, abre-se um leque de novas possibilidades que podem ser apropriadas pelo debate mais amplo sobre a construção de futuros mais sustentáveis (Seyfang; Smith, 2007; Smith; Fressoli; Thomas, 2014; Roysen; Mertens, 2016).

\section{Ecovilas como um movimento comunitário global}

As ecovilas estão presentes em todos os continentes, e estão conectadas por meio da Rede Global de Ecovilas (Global Ecovillage Network, GEN), que abarca 7100 comunidades em 116 países (Global Ecovillage Network, 2021). A GEN trabalha em cooperação com governos, agências da ONU, empresas e outras partes interessadas para catalisar o desenvolvimento das comunidades e alcançar os Objetivos de Desenvolvimento Sustentável (ODS) e o cumprimento do Acordo de Paris sobre mudanças climáticas, com uma abordagem comunitária para erradicar a pobreza, restaurar o ambiente natural e garantir que as necessidades humanas básicas sejam atendidas. Desde 2000, a GEN tem status consultivo no Conselho Econômico e Social da ONU (Global Ecovillage Network, 2020).

Durante a $25^{\mathrm{a}}$ edição da Conferência das Partes (COP) da Convenção-Quadro da ONU sobre Mudança do Clima, realizada em 2019, a GEN assinou memorandos de entendimento com diversos países do Sul Global para a implementação nacional de programas de desenvolvimento de ecovilas (Ecovillage Development Programmes, EDP), ampliando a rede de projetos globais em busca da transição e de um futuro regenerativo. Ao todo, 22 governos já expressaram interesse no desenvolvimento de ecovilas em larga escala.

Além de um escritório central localizado na ecovila de Findhorn, na Escócia, a GEN se 
distribui em redes continentais autônomas, mas integradas: GEN Europe, GEN Oceania and Asia (Genoa), GEN North America (GENNA), GEN Africa e, na América Latina, o Conselho de Assentamentos Sustentáveis da América Latina (CASA Latina), além de uma rede transversal da juventude (NEXT GEN). Cada rede continental é composta por redes nacionais. No Brasil, o movimento das ecovilas está articulado pela rede CASA Brasil (2020), que tem buscado fomentar a troca de ideias e ações conjuntas entre as ecovilas.

Vale ressaltar que as ecovilas brasileiras também têm apresentando uma tendência a ampliar o diálogo e a colaboração com agentes externos, incluindo instâncias governamentais e a atuação em conselhos de políticas públicas. $25 \%$ das ecovilas brasileiras participam de conselhos de meio ambiente e $22 \%$ participam de conselhos gestores de unidades de conservação (Roysen; Mertens, 2017). Elas têm ajudado, portanto, a fortalecer a luta pela preservação ambiental, especialmente nas pequenas cidades, já que quase $80 \%$ dos municípios que abrigam essas iniciativas são de pequeno porte (Arruda, 2018). Salienta-se ainda que o diálogo entre o movimento das ecovilas e outros movimentos populares de luta por justiça socioambiental contribuem para potencializar o debate sobre sustentabilidade, regeneração e ações de impacto positivo, com benefícios a toda a sociedade.

As ecovilas propõem modos de vida que dialogam com as comunidades locais na busca por arranjos sociais e produtivos que possam viabilizar novos modos e meios de existência genuinamente sustentáveis. No entanto, o estabelecimento desses novos arranjos - desejáveis no contexto da crise socioambiental contemporânea -, esbarra em obstáculos de ordem legal para se materializar espacialmente no Brasil. A seguir, expomos a situação das ecovilas no atual ordenamento territorial brasileiro e seus desafios.

\section{Ecovilas e o ordenamento territorial brasileiro}

As ecovilas enfrentam dificuldades relacionadas ao uso e à ocupação do solo, especialmente devido à dicotomia urbano-rural que permeia a legislação brasileira e que gera, portanto, ilegalidade e insegurança jurídica às iniciativas existentes no Brasil, podendo, inclusive, responsabilizar as ecovilas por parcelamento ilegal de solo. As ecovilas são uma "novidade" para o Estado e, portanto, não se encaixam no ordenamento jurídico vigente. Essa dicotomia urbanorural atribui à zona rural a função de local de produção agropecuária ou de conservação da natureza, negando à zona rural a sua dimensão social (Silva, 2020). Em sua pesquisa, Silva explica o principal entrave jurídico enfrentado pelas ecovilas brasileiras:

O parcelamento para fins rurais é o que se destina à exploração econômica da terra (agrícola, pecuária, extrativa ou agroindustrial), segundo o Estatuto da Terra (1964). No entanto, o parcelamento para fins urbanos é o que se destina à urbanização, edificação e à ocupação com finalidade de habitação, indústria ou comércio e é disciplinado pela Lei Federal $n^{\circ} 6.766$, de 19 de dezembro de 1979, que dispõe sobre o 
parcelamento do solo urbano. O Art. $3^{\circ}$ da Lei $n^{\circ} 6.766 / 79$, estabelece que o parcelamento do solo para fins urbanos somente é admitido em zonas urbanas, de expansão urbana ou de urbanização específica, assim definidas pelo plano diretor ou em lei municipal. A lei do parcelamento excluiu de sua órbita de aplicação os loteamentos para fins rurais. Assim definido por lei municipal, afastada está qualquer possibilidade de se instalar um loteamento, ou desmembramento destinado a chácaras ou sítios de recreio na zona rural. Nesse sentido, surge então o quarto entrave: a responsabilização criminal dos membros das ecovilas com consequente embargo das atividades e multa. [...]. Caso a autoridade pública entenda que há urbanização no meio rural, os membros da ecovila podem ser responsabilizados criminalmente nos termos dos artigos 50 e 51 da Lei $n^{\circ} 6.766 / 79$ (Silva, 2020, p. 141).

Todos os imóveis rurais particulares na zona rural devem, de alguma forma, destinar-se à exploração extrativa agrícola, pecuária ou agroindustrial para cumprir a função social da propriedade rural constitucionalmente estabelecida e legalmente disciplinada (Silva, 2020). Além disso, é necessário que haja produção em 80\% da área aproveitável. "A Lei nº 8.629/93 considera efetivamente utilizadas as áreas: plantadas com produtos vegetais; de pastagens nativas e plantadas; as áreas de exploração extrativa vegetal ou florestal; de exploração de florestas nativas; sob processos técnicos de formação ou recuperação de pastagens ou de culturas permanentes" (Silva, 2020, p. 145).

Portanto, se um proprietário de terra decide usar os $80 \%$ de área aproveitável para remover a mata nativa e plantar braquiárias para o gado, ele estará em conformidade com a legislação. Por outro lado, se os proprietários querem usar o terreno para construir casas sustentáveis em combinação com áreas destinadas à conservação da biodiversidade, pequenas áreas de plantio orgânico e atividades de educação ambiental e ecoturismo, por exemplo, como acontece nas ecovilas, eles recaem na ilegalidade.

Dessa forma, um dos principais entraves para as ecovilas ocuparem a propriedade rural legalmente é a necessidade de manter o destino da propriedade conforme a produtividade prevista nos ditames legais de forma a comprovar, de forma inequívoca, o uso rural da terra. No entanto, as ecovilas, "[..] enquanto nova estrutura societária, superam a lógica maniqueísta rural ou urbana dos assentamentos humanos modernos. Trata-se inegavelmente de considerar a reorganização da ocupação do solo para fins de assentamentos humanos" (Silva, 2020, p. 144). Segundo o autor:

[...] nas práticas diárias das ecovilas estão presentes, dentre outros, o exercício e a proteção de diversos direitos fundamentais como a propriedade, educação, saúde, trabalho, moradia e meio ambiente. As ecovilas vêm evoluindo na busca pela justiça social que vem sendo reconhecida como essencial à sustentabilidade. Como apresentado, o movimento de ecovilas emerge como uma alternativa aos padrões insustentáveis das sociedades modernas [...]. O crescimento de agrupamentos humanos organizados em ecovilas é recente e, portanto, pode ser recepcionado pelo ordenamento jurídico brasileiro (Silva, 2020, p. 163). 
O "novo rural brasileiro" já vem sendo documentado há duas décadas com a emergência expressiva das atividades rurais não-agrícolas e da pluriatividade no meio rural brasileiro, incluindo serviços como ecoturismo e outras atividades relacionadas à preservação ambiental (Carneiro, 2008; Silva, 2020). Como argumenta Carneiro (2008, p. 30), a "[...] noção de rural corresponde a construções simbólicas pertencentes a diferentes universos culturais que thes atribuem significados distintos". Entendemos, considerando este argumento, que o "rural" como concebido nos termos da atual legislação brasileira é (ou foi) elaborado a partir de construções simbólicas específicas, geralmente reduzindo o rural à atividade agrícola, à escassez e ao atraso. No entanto, essas construções simbólicas não dão mais conta da complexidade imbricada nos "rurais" diversos do Brasil, o que nos leva à necessidade de atualização (ou revisão) do "rural legal".

As ecovilas são uma das formas de expressão dessas novas ruralidades que extrapolam a dicotomia urbano-rural, desenvolvendo tanto atividades convencionalmente ligadas à ruralidade (atividades agrícolas e de conservação) quanto atividades convencionalmente ligadas à urbanidade (turismo, educação, moradia, convivência etc.). Embora sejam um fenômeno crescente no Brasil, as ecovilas ainda permanecem à margem do ordenamento territorial brasileiro, que não acompanhou as dinâmicas associadas à ruralidade contemporânea.

O uso e ocupação do solo no Brasil, seja em áreas urbanas ou rurais, tem se dado a partir de legislações específicas, que datam desde o Decreto-Lei n58/37 e o Decreto $n^{\circ} 3.079 / 38$. Antes da Constituição Federal de 1988, a Lei n6766/79, lei federal de parcelamento do solo, tratou da questão do parcelamento de áreas urbanas. Já em 1999, a Lei n9785, no Art. $3^{\circ}$, modificou a Lei $n^{\circ} 6.766$, de 19 de dezembro de 1979, que passa a vigorar com as seguintes alterações: "Art. $3^{\circ}$ Somente será admitido o parcelamento do solo para fins urbanos em zonas urbanas, de expansão urbana ou de urbanização específica, assim definidas pelo plano diretor ou aprovadas por lei municipal".

O movimento pela Reforma Urbana, constituído por uma série de entidades da sociedade civil, buscou colocar na Constituição Federal de 1988 o conceito de função social da propriedade, onde os interesses coletivos preponderam em relação aos interesses individuais. Dessa forma, com a Constituição de 1988, com os requisitos legais colocados nos artigos 182 e 183, abriu-se caminho para uma nova legislação urbanística que atribuiu maior autonomia aos municípios na definição de regras urbanísticas específicas, especialmente a partir da elaboração do Plano Diretor Municipal (PDM).

O Estatuto da Cidade (Lei Federal $n^{\circ} 10.257 / 01$ ) é a lei brasileira de desenvolvimento que regulamenta o capítulo da política urbana da Constituição Brasileira de 1988. Ele define as diretrizes gerais que devem ser observadas pela União (Governo Federal), pelos estados (Governos Estaduais) e municípios (Governos Municipais) para a promoção da política urbana, voltada a garantir o pleno desenvolvimento das funções sociais da propriedade urbana e da 
cidade, o direito a cidades sustentáveis e o desenvolvimento de gestões democráticas nas cidades.

Segundo o Estatuto da Cidade, no seu capítulo III, o PDM, aprovado por lei municipal, é o instrumento básico da política de desenvolvimento e expansão urbanos, devendo englobar todo o território do município. Esse plano deve ser revisto a cada dez anos de forma a incluir, no processo, a promoção de audiências públicas e debates com a participação da população e de associações representativas dos vários segmentos societários.

A elaboração participativa do PDM oferece, portanto, um caminho para a inclusão das ecovilas no zonamento dos municípios. Para isso, é imprescindível a convocação de todas as entidades, organizações, conselhos e grupos constituídos da sociedade civil para garantir a efetiva participação e transparência nos processos e o acesso às informações pertinentes à construção coletiva do plano, das instâncias de fiscalização e de sua posterior implementação. A metodologia a ser colocada em prática deve ser construída a partir da criação do Núcleo Gestor do Plano Diretor, que garanta a efetiva participação da sociedade civil, seja por setor de atuação, seja por localização em áreas específicas do município.

\section{Proposta para a inserção das ecovilas no Plano Diretor Municipal}

No PDM, o macrozoneamento corresponde à "divisão do território em unidades territoriais que expressem o destino que o município pretende dar às diferentes áreas da cidade" (Rolnik; Saule Júnior, 2001, p. 41). Trata-se de uma cartografia de referência para o uso e a ocupação do solo circunscritos ao perímetro municipal, fixando as regras fundamentais de orientação ao desenvolvimento territorial das cidades. Define, por exemplo, áreas adensáveis e não adensáveis de acordo com compatibilidade destas com a capacidade da infraestrutura instalada, com as exigências de preservação do patrimônio histórico e ambiental e com a qualidade de vida que as condições do meio físico local e as características da ocupação já existente podem proporcionar (Rolnik; Saule Júnior, 2001). Os instrumentos de regularização fundiária baseiamse no macrozoneamento, que estabelece zonas que delimitam o perímetro urbano, o rural e outras zonas específicas, de modo a atender as diretrizes gerais estabelecidas pelo Estatuto da Cidade (lei $\mathrm{n}^{\circ} 10.257$, de 10 de julho de 2001) para a política urbana no país. A estrutura e a divisão das zonas do Macrozoneamento Urbano, Rural e Macrozonas Especiais são elaboradas com base em estudos ambientais, sociais, de disponibilidade e qualidade de infraestrutura, de equipamentos públicos e de densidade populacional. Cabe notar que, dentro das zonas de urbanização específica, o município pode propor a criação de uma "Zona de Agroecologia e Ecovilas", que pode estar contida nos perímetros urbano, de expansão urbana ou rural, a ser definida e delimitada no Mapa de Macrozoneamento do Município.

As delimitações das Macrozonas têm por objetivos:

1) Incentivar, coibir ou qualificar a ocupação, compatibilizando a capacidade e qualidade 
de infraestrutura, qualidade de vida e a proteção ao meio ambiente;

2) Conter a expansão da área urbana, que acarrete degradação socioambiental;

3) Minimizar os custos de implantação e manutenção e a otimização da infraestrutura urbana e serviços públicos essenciais;

4) Ordenar o processo de expansão territorial e o desenvolvimento do Município.

São parâmetros urbanísticos a serem definidos no Macrozoneamento:

1) Coeficiente de área verde mínima da gleba a ser parcelada ou loteada;

2) Coeficiente de aproveitamento (área a ser construída, incluindo verticalização) básico, mínimo e máximo;

3) Taxa de ocupação máxima (porcentagem ocupada do terreno);

4) Taxa de permeabilidade mínima;

5) Tamanho mínimo de lote;

6) Número de pavimentos máximos;

7) Percentual de área institucional mínima.

A Macrozona de Agroecologia e Ecovilas, enquanto zona de urbanização específica voltada prioritariamente para projetos de produção de alimentos orgânicos, prática de agroecologia e agrofloresta, pecuária de pequena escala, ecovilas e assentamentos específicos de comunidades em transição, pode ter como usos permitidos: Residencial Unifamiliar, residencial multifamiliar, comercial, serviços, industrial e institucional.

Os parâmetros urbanísticos para a Zona de Agroecologia e Ecovilas deverão ser definidos em função das características específicas de cada município e das comunidades interessadas. Por exemplo, nas propostas de planos diretores dos municípios de Esmeraldas e Alvorada de Minas, ambos no estado de Minas Gerais, adotou-se os seguintes parâmetros:

1) Tamanho mínimo de lote $=1000 \mathrm{~m}^{2}$ (mil metros quadrados);

2) Testada mínima de $20 \mathrm{~m}$ (vinte metros);

3) Largura mínima de calçadas de $3 \mathrm{~m}$ (três metros);

4) Largura mínima de vias de 6 a $10 \mathrm{~m}$ (seis a dez metros);

5) T.o. máximo (taxa de ocupação) $=40 \%$ (quarenta por cento);

6) T.o. mínima (taxa de permeabilidade) $=30 \%$ (trinta por cento);

7) C.v. mínimo (coeficiente verde) $=20 \%$ (vinte por cento);

8) C.a. básico-cab (coeficiente de aproveitamento básico) $=0.5$ (meio);

9) C.a. máximo cam (coeficiente de aproveitamento máximo) = 1.0 (um);

10) C.a. mínimo cami (coeficiente de aproveitamento mínimo) $=0.5$ (meio).

11) Número de pavimentos máximos $=2$ (dois) 
O caminho para garantia de uso e ocupação do solo, parcelamento e adequação do processo legislativo urbanístico deve começar pela participação efetiva das ecovilas na elaboração do Plano Diretor Participativo do município. Cabe a inserção da área ocupada ou a ser ocupada pela ecovila ou similar, como área de urbanização específica, conforme Lei $n^{\circ} 9785 / 99$, Art $3^{\circ}$. As características específicas do assentamento definirão se essa Zona de Urbanização específica, voltada para Agroecologia e Ecovilas será urbana ou rural.

Além das especificidades de categorias de uso, parâmetros urbanísticos, e demais parâmetros necessários, devem ser definidos parâmetros de licenciamento ambiental municipal, a serem implementados conforme a definição do Plano Diretor Municipal e legislação complementar pertinente.

Ações de licenciamento ambiental e fiscalização devem ocorrer de forma clara e articulada, com as devidas funções integradas, no sentido de se valorizar e facilitar esse tipo de assentamento sustentável. Os caminhos legais existentes precisam e devem ser aprimorados para assegurar que tais comunidades possam ser implantadas dentro da legalidade, com apoio dos órgãos municipais, estaduais e federais. Nesse sentido, a representatividade das ecovilas na elaboração participativa dos PDM, bem como a sua atuação política nas demais instâncias de participação social e de articulação junto aos atores locais, também se configuram como ações cruciais para o avanço desse processo.

\section{Como identificar uma ecovila?}

É importante distinguir as ecovilas de outros modelos de condomínios e loteamentos. Existem muitos empreendimentos que incorporam nas suas infraestruturas e edificações diversas tecnologias ecoeficientes, porém não incluem as dimensões social/comunitária, cultural/espiritual e econômica da sustentabilidade como propõem as ecovilas. Com base na literatura científica nacional e internacional, bem como nas experiências empíricas historicamente acumuladas pelo próprio movimento brasileiro de ecovilas, propomos aqui um conjunto de parâmetros que possam orientar os gestores públicos na identificação e caracterização das ecovilas, com vistas a incorporar este modelo nos Planos Diretores Municipais.

São características do modelo de ocupação aqui denominado ecovila:

1) Propriedade compartilhada em nome de uma associação e/ou cooperativa. As ecovilas são iniciativas provenientes da sociedade civil, situando-se na área de atuação do Terceiro Setor. Ou seja, não se tratam de agentes imobiliários, nem construtoras ou incorporadoras de terras, mas, sim, de cidadãos que se reúnem em torno de um mesmo propósito;

2) Modelos inclusivos e equânimes de tomada de decisão por todos os seus membros, registrados em estatuto;

3) Taxa de impermeabilização do solo inferior a $40 \%$; 
4) Encaminhamento de resíduos orgânicos para estações de compostagem ou tratamento e disposição final dos resíduos no próprio terreno de forma ambientalmente adequada; e reutilização ou encaminhamento para reciclagem de $100 \%$ dos resíduos recicláveis produzidos na propriedade (desde que atendidos por cadeias logísticas de reciclagem existentes no município);

5) Tecnologias descentralizadas e ecológicas de tratamento das águas cinzas (tal como um círculo de bananeiras) e negras (tais como biodigestores, bacias de evapotranspiração e banheiros secos);

6) Construções que visam a eficiência energética e a redução do consumo de recursos naturais, utilizando técnicas construtivas com materiais locais e arquitetura bioclimática, de forma a reduzir a necessidade de iluminação artificial e resfriamento e/ou aquecimento artificial do ambiente, dentre outras;

7) Tecnologias de uso racional dos recursos renováveis, tais como: captação de energia solar e eólica, captação de água das chuvas, biodigestores, aquecimento solar de água etc.;

8) Iniciativas que estimulem o uso compartilhado de ferramentas, materiais, recursos e energia, tais como: provisão de áreas de uso comum (cozinhas, lavanderias, jardins, hortas, espaços de leitura, lazer), organização de grupos de caronas, carros de uso compartilhado, almoços coletivos, feiras de trocas, dentre outras práticas comunitárias;

9) Restauração florestal por meio da criação de áreas de preservação, ações de reflorestamento com espécies nativas ou conservação por meio de práticas agroflorestais em, pelo menos, $30 \%$ da propriedade, incluindo Áreas de Preservação Permanente (APP) e Reservas Particulares do Patrimônio Natural (RPPN);

10) Pequenos negócios sustentáveis, tais como: centros pedagógicos, hospedagem, restaurantes, processamento e/ou beneficiamento de produtos naturais localmente produzidos, centros terapêuticos e de saúde complementar, entre outros.

Em vista do exposto, argumentamos também que as ecovilas assim identificadas tenham prioridade em ações governamentais, existentes ou que vierem a existir, de incentivo à implementação de empreendimentos comunitários ambientalmente responsáveis, tais como: promoção de mecanismos de financiamento (obtenção de crédito, editais de fomento), Pagamento por Serviços Ambientais (PSA), subsídios para produtos e serviços, isenção de taxas e assistência técnica.

\section{Considerações Finais}

Vimos neste artigo que as ecovilas são assentamentos humanos sustentáveis originados na sociedade civil que desenvolvem soluções inovadoras nas diversas dimensões da sustentabilidade. Ainda que a Constituição Federal Brasileira afirme o direito de todos ao meio ambiente ecologicamente equilibrado e imponha ao poder público e à coletividade o dever de 
preservá-lo, a lógica binária da legislação brasileira, no que tange ao uso e ocupação dos solos urbano e rural, gera uma série de dificuldades ao modelo de desenvolvimento sustentável proposto pelas ecovilas. A dicotomia urbano-rural que permeia a legislação brasileira, baseada em construções simbólicas que não mais refletem a realidade contemporânea, não permite que a zona rural possa, também, comportar atividades de moradia, convivialidade, conservação ambiental, educação e ecoturismo, além da produção agropecuária.

Torna-se, então, urgente que o ordenamento jurídico brasileiro recepcione as ecovilas como um modelo de assentamento sustentável, replicável em diferentes realidades municipais. Neste artigo, indicamos uma das formas pelas quais isso pode ser realizado, por meio da criação de zonas de urbanização específica, aqui chamadas de "Zona de Agroecologia e Ecovilas", nos Planos Diretores Municipais. Tais zonas especiais podem ser inscritas no perímetro urbano, no de expansão urbana, no perímetro rural e, ainda, nas fronteiras entre essas áreas.

Por fim, diante da multiplicação de empreendimentos imobiliários que se apropriam do conceito de "ecovila" ou "ecovillage", mas que não geram mudanças significativas nos modos de vida, definimos critérios que caracterizam as ecovilas. Mais do que o uso do nome "ecovila" ou "ecovillage" para obter vantagem competitiva no mercado imobiliário, é a transformação da paisagem, das práticas e dos relacionamentos induzida pelas ecovilas que agregam valor ao território, conferindo-lhe maior sustentabilidade.

Esperamos ter contribuído para que o desenvolvimento de ecovilas assim identificadas seja seriamente considerado pelos gestores públicos como estratégia para o cumprimento do artigo 225 da Constituição Federal Brasileira e para o esforço coletivo em prol da realização dos Objetivos do Desenvolvimento Sustentável no país.

\section{Agradecimentos}

Os autores agradecem os comentários, as sugestões e os questionamentos enviados pelos membros das ecovilas sobre o pré-print disponibilizado via ResearchGate no primeiro semestre de 2021 e a contribuição de Taisa Mattos na revisão do texto final.

\section{Colaboradores}

R. ROYSEN colaborou com a construção colaborativa do texto, conteúdo, redação e revisão; B. M. ARRUDA, R. A. A. FONSECA e L. G. M. F. DUARTE colaboraram com o conteúdo, redação e revisão; R. FERREIRA e M. A. A. ALVARENGA colaboraram com o conteúdo e redação.

\section{Referências}

Arruda, B. M. O fenômeno de ecovilas no brasil contemporâneo. 2018. 204 f. Dissertação (Mestrado) - Pontifícia Universidade Católica de Campinas, Campinas, 2018.

Belleze, G. et al. Ecovilas brasileiras e indicadores de desenvolvimento sustentável do IBGE: 
uma análise comparativa. Ambiente \& Sociedade, v. 20, n. 1, p. 227-244, 2017.

Boyer, R. W. Grassroots innovation for urban sustainability: comparing the diffusion pathways of three ecovillage projects. Environment and Planning A: Economy and Space, v. 47, n. 2, p. 320337, 2015. doi:10.1068/a140250p

Boyer, R. Achieving one-planet living through transitions in social practice: a case study of Dancing Rabbit Ecovillage. Sustainability: Science, Practice and Policy, v. 12, n. 1, p. 1-6, 2016.

Brasil. [Constituição (1988)]. Constituição da República Federativa do Brasil. Brasília, DF: Senado $\quad$ Federal, $1988 . \quad$ Disponível em: https://www2.senado.leg.br/bdsf/bitstream/handle/id/518231/CF88_Livro_EC91_2016.pdf.

Acesso em: 9 jan. 2020.

Capello, G. Meio ambiente e ecovilas. São Paulo: Senac, 2013.

Caravita, R. I. "Somos todos um": vida e imanência no movimento comunitário alternativo. 2012. 232 f. Dissertação (Mestrado em Antropologia Social) - Universidade Estadual de Campinas, Campinas, 2012.

Carneiro, M. J. "Rural" como categoria de pensamento. Ruris, v. 2, n. 1, p. 9-38, 2008.

Casa Brasil. Conselho de Assentamentos Sustentáveis da América Latina: Rede Casa Brasil. [S.I.]: Casa Brasil, 2020. Disponível em: https://www.redecasabrasil.org/. Acesso em: 20 out. 2020.

Christian, D. L. Starting a new ecovillage: 'structural conflict' \& nine ways to resolve it. In: Joubert, K. A.; Alfred, R. (ed.). Beyond you and me: inspirations and wisdom for building community. Hampshire: Permanent Publications, 2007. p. 49-57.

Daly, M. Quantifying the environmental impact of ecovillages and co-housing communities: a systematic literature review. Local Environment, v. 22, n. 11, p. 1358-1377, 2017.

Dawson, J. From Islands to networks: the history and future of the ecovillage movement. In: Lockyer, J.; Veteto, J. R. (ed.). Environmental anthropology engaging ecotopia: bioregionalism, permaculture, ecovillage. Nova lorque: Berghahn Books, 2013. p. 217-234.

Gaia Education. EDE: ecovillage design education. 3. ed. [S.I.]: Global Ecovillage Network, 2005.

Global Ecovillage Network. GEN Homepage Institucional, Available from: https://ecovillage.org/our-work/advocacy/. Cited: Oct. 20, 2020.

Global Ecovillage Network. 2020 Annual Report. Available from: https://ecovillage.org/about/reports/. Cited: Dec. 17, 2021.

Kasper, D. V. S. Redefining community in the ecovillage. Human Ecology Review, v. 15, n. 1, p. 12-24, 2008.

Kirby, A. Redefining social and environmental relations at the ecovillage at Ithaca: A case study. Journal of Environmental Psychology, v. 23, n. 3, p. 323-332, 2003.

Kunze, I. Transformative social innovation narrative of the ecovillage of Schloss Tempelhof (TH): Transit: Grant Agreement, n. 613169, 2015. Available from: http://www.transitsocialinnovation.eu/. Cited: Dec. 17, 2021.

Jackson, R. The Ecovillage Movement. Permaculture Magazine, n. 40, 2004.

Litfin, K. T. Ecovillages: Lessons for sustainable community. Malden: Polity Press. 2014.

Loezer, L. Enhancing Sustainability at the Community Level: Lessons from American EcoVillages. Dissertação (Master degree in Archtecture) - University of Cincinnati, 2011.

Matheus e Silva, L. F. Viver de forma sustentável ou contribuir para a sustentabilidade do capital? As contradições que permeiam a práxis das ecovilas em tempos neoliberais. Geografias, v. 10, n. 1, p. 41-53, 2014.

Mattos, T. P. Ecovilas: a construção de uma cultura regenerativa a partir da práxis de Findhorn, 
Escócia. 2015. 250 f. Dissertação (Mestrado em Psicossociologia de Comunidades e Ecologia Social) - Universidade Federal do Rio de Janeiro, Rio de Janeiro, 2015.

United Nations. Ecovillage Initiative for Achieving the SDGs. [S.I.]: UN, [20--]. Available from: https://sustainabledevelopment.un.org/partnership/?p=11943. Cited: Jan. 14, 2021.

Rolnik, R.; Saule Júnior, N. Estatuto da Cidade: guia para implementação pelos municípios e cidadãos. São Paulo: Instituto Pólis, 2001.

Roysen, R. Desenvolvimento e difusão de práticas sociais sustentáveis no nicho das ecovilas no Brasil: o papel das relações sociais e dos elementos das práticas. 2018. 209 f. Tese (Doutorado em Desenvolvimento Sustentável) - Universidade de Brasília, Brasília, 2018.

Roysen, R.; Mertens, F. Difusão de práticas sociais sustentáveis em nichos de inovação social de base: o caso do movimento das ecovilas. Desenvolvimento e Meio ambiente, v. 39, p. 275295, 2016.

Roysen, R.; Mertens, F. O Nicho das ecovilas no Brasil: comunidades isoladas ou em diálogo com a sociedade? Fronteiras: Journal of Social, Technological and Environmental Science, v. 6, n. 3, p. 99-121, 2017.

Roysen, R.; Mertens, F. New normalities in grassroots innovations: the reconfiguration and normalization of social practices in an ecovillage. Journal of Cleaner Production, v. 236, n. 8, 18, 2019. https://doi.org/10.1016/j.jclepro.2019.117647.

Salazar, C. A. P. Participación y acción colectiva en los movimientos globales de ecoaldeas y permacultura. Revista Latinoamericana de Psicología, v. 45, n. 3, p. 401-413, 2013.

Santos-Júnior, S. J. Zelosamente habitando a Terra: ecovilas genuínas, espaço geográfico e a construção de lugares zelosos em contextos contemporâneos de fronteiras paradigmáticas. 2016. 443 f. Tese (Doutorado em Geografia) - Universidade Federal da Bahia, Salvador, 2016.

Seyfang, G.; Smith, S. Grassroots Innovations for Sustain-able Development: Towards a New Research and Policy Agenda. Environmental Politics, v. 16, n. 4, p. 584-603, 2007.

Sherry, J. The impact of community sustainability: a life cycle assessment of three ecovillages, Journal of Cleaner Production, v. 237, 117830, 2019, 1-13. https://doi.org/10.1016/j.jclepro.2019.117830.

Silva, J. V. Ecovilas como novos sujeitos de direitos: possibilidades e entraves legais no uso e ocupação do solo rural no Brasil. 2020. 207 f. Dissertação (Mestrado em Ciências Humanas) Universidade Federal dos Vales do Jequitinhonha e Mucuri, Diamantina, 2020.

Smith, A.; Fressoli, M.; Thomas, H. Grassroots innovation movements: challenges and contributions. Journal of Cleaner Production, v. 63, p. 114-124, 2014. https://doi.org/10.1016/j.jclepro.2012.12.025.

Swilling, M.; Annecke, E. Building sustainable neighbourhoods in South Africa: learning from the Lynedoch case. Environment and Urbanization, v. 18, n. 2, p. 315-332, 2006.

UN-Habitat. Practice Details: Findhorn Ecovillage. [S.I.]: UN-Habitat, 2017. Availlable from: https://mirror.unhabitat.org/bp/bp.list.details.aspx?bp_id=4610. Cited: Jan. 14, 2021.

Veteto, J. R.; Lockyer, J. Environmental anthropology engaging permaculture: moving theory and practice toward sustainability. Agriculture, v. 30, n. 1-2, p. 47-58, 2008.

\section{Como citar este artigo/How to cite this article}

Roysen, R. et al. Zonas de Agroecologia e Ecovilas: uma proposta para os Planos Diretores Municipais. Sustentabilidade: Diálogos Interdisciplinares, v. 2, e215527, 2021. https://doi.org/10.24220/26757885v2e2021a5527

Recebido em 9 de dezembro de 2021 e aprovado em 14 de dezembro de 2021. 